\title{
Recent Trends and Development of Heuristic Artificial Intelligence Approach in Mechanical System and Engineering Product Design
}

\author{
Ahmed J. Obaid $^{1 *}$, Shubham Sharma ${ }^{2,3}$ \\ ${ }^{1}$ Department of Computer Science, Faculty of Computer Science and Mathematics, University of Kufa, Najaf, Iraq \\ ${ }^{2}$ Department of Mech. Engineering, CSIR-Central Leather Research Institute, RCED, Leather complex, Jalandhar, 144021, India \\ ${ }^{3}$ Department of Mech. Engineering, IKG Punjab Technical University, Jalandhar-Kapurthala Road, Kapurthala, 144603, Punjab, India
}

DOI: $10.36348 /$ sjet.2020.v05i02.008

| Received: 01.02.2020 | Accepted: 08.02.2020 | Published: 29.02.2020

*Corresponding author: Ahmed J. Obaid

Abstract

The utility of Artificial Intelligence (AI) to design is mainly concerned with trying to make systems smarter through getting to know how to enable them to represent and control the real global understanding. It is likewise about contemplating studying how designers observe human intelligence to design, and with looking to make computer aids to design greater knowledgeable. Presently the principle topics inside the utility of Artificial Intelligence are to discover the formal illustration of the layout information, and additionally to expand strategies for reasoning with or applying this expertise. Computers have historically been capable of cope with the application of the legal guidelines of science, expressed in mathematical techniques. Artificial Intelligence (AI) mainly permits illustration of heuristic (or rule based) understanding this is less effortless or simple to explicit the use of mathematical methods. This, a part of artificial intelligence is in particular concerned with the development of such representations is called professional structures or more typically information based totally systems. This paper covers the various steps and ideas involved in adding synthetic Intelligence to the layout of mechanical structures. In this paper, a broad audit with respect to the uses of the Artificial Intelligence, in conjunction with its connection between the mechanical building for the method of mechanical imperfections identification and design layout configuration is proposed. This paper accommodates the précis or synopsis related to the precise utilizations of Artificial Intelligence in the field of mechanical Eng. Several applications, like errors identification, Analytic indicative Framework machine, mechanical shape and structure investigation, and mechanical layout plan are notably inspected. This study uncovers that the Artificial Intelligence based smart system is broadly utilized generally in the total mechanical Engineering designing area. This paper likewise presumes that the Mechanical Engineering and designing field can be effectively combined with different other Artificial Intelligence based innovation era to make it progressively successful to improve in the mechanical framework.

Keywords: Artificial Intelligence, Design, Computer aids, Mathematical approaches, Mechanical systems, Errors and defects identification, Analytic indicative Framework machine, mechanical shape and structure analysis.

Copyright @ 2020: This is an open-access article distributed under the terms of the Creative Commons Attribution license which permits unrestricted use, distribution, and reproduction in any medium for non-commercial use (NonCommercial, or CC-BY-NC) provided the original author and source are credited.

\section{INTRODUCTION}

There are a number of strands of research into artificial intelligence (AI). Only one part of the activity involves trying to produce the systems which simulate intelligent behavior. The other work involves investigating the nature of intelligence, and trying to make systems smarter by learning how to enable them to represent and manipulate real world knowledge. A primary concern of $\mathrm{AI}$ is writing down descriptions of the given area in such a way that an intelligent system can come to new conclusions about its environment by formally manipulating these descriptions [1-3]. The main characteristic of $\mathrm{AI}$ is the representation of the domain knowledge. This paper focuses on the various concepts of AI system. Also a case of application of AI in gearbox design is discussed here.

\section{KNOWLEDGE BASED SYSTEMS}

Knowledge primarily based engineering, a brand new development of Artificial Intelligence in handling with the learning data, is especially focused on the way to constitute information or data and workout the answer intellectually with the aid of using the mainframe computers. Information engineering is the essential theoretical base of new era computers, which makes the exploration studies of Artificial Intelligence transfer from hypothesis principle to software, from modelling primarily based on reasoning to modelling based on expertise and learning [2-4]. Its crucial motive 
is to develop artificial Intelligence device framework, compliment and broaden the mind's capacity or characteristic and begin an age where in individuals, humans and computers think together.

\section{INFERENCE ENGINE}

The extraction of statistics from the learning databaseor knowledge base is done by way of a framework referred to as an inference engine, that's commonly separate from the information expertise base itself $[5,6]$. Inference commonly entails seek and matching within the expertise and information base so as to attempt to meet an objective.

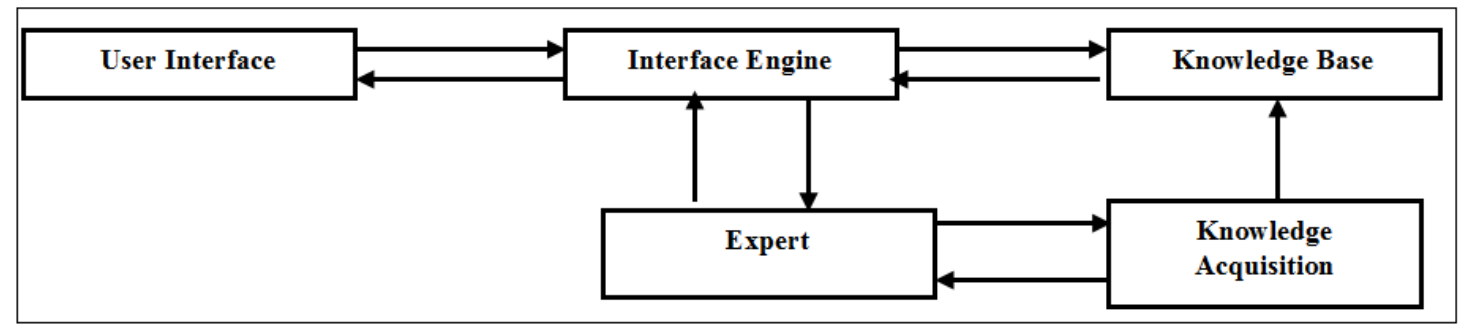

Fig-1: Elements of a knowledge based system

\section{KNOWLEDGE-BASED SYSTEM FOR \\ MECHANICAL CAD DESIGN}

The potential of current mechanical computer aided design framework in representing design for element, assembly and drafting/drawing is entrenched or well installed. Parametric design and feature based modelling are common technologies found in existing 3D CAD system. There are two common approaches of 3D design: a new design or/and modification to existing design (Figure-2). For new design, the designer will have to model the part from scratch, starting either by 2D sketch and then extrude/revolve/loft/sweep; or using $3 \mathrm{D}$ primitive to perform Boolean operations to form $3 \mathrm{D}$ part. These are then followed by other feature operations such as hole, fillet, chamfer, etc. Applying assembly constraints to build a 3D assembly then forms various parts together. While for modification to existing design, dimensions and other properties are changed/varied to form new part and assembly [1]. The underlying technology for Parametric Design is dimension driven geometry where changes in geometry are generated by changes in dimensions' value, constraint and relation/equation In Parametric CAD system, geometric entities of models are connected with parameters. Thus, selecting the right parameters that meet the design requirements is essential role of design engineer. The experience, knowledge and expertise of a $\mathrm{CAD}$ designer covering areas of product geometry and properties are crucial in producing design right the first time and cutting short the product development cycle.

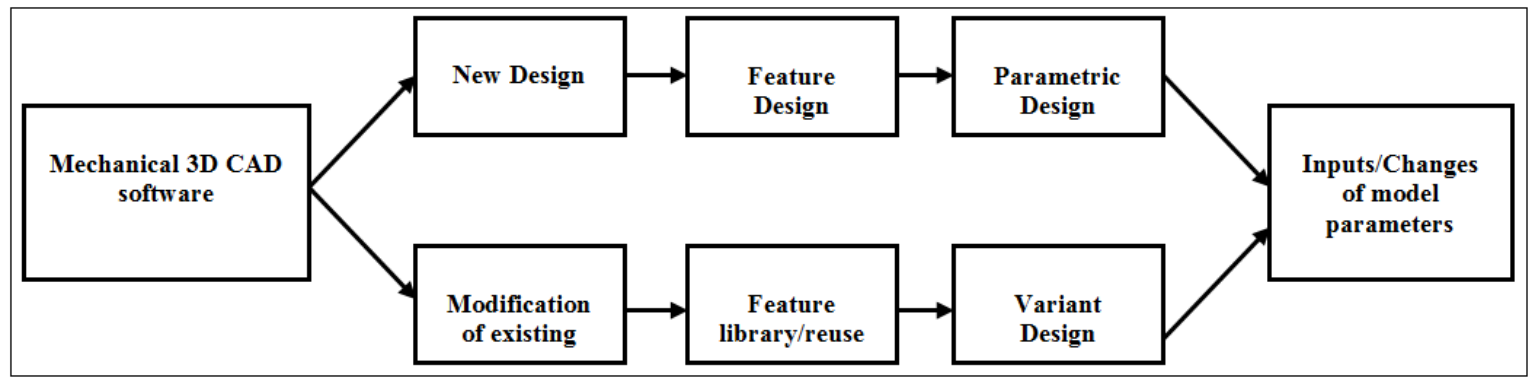

Fig-2: Common approaches of 3D design

A knowledge-based system that could capture and retain his/her expertise gained in the past designs and re-apply to the future designs is vital important.

\section{APPROACHES TO THE APPLICATION OF AI IN DESIGN}

There are several classes of design problems for which AI techniques are particularly useful, these are discussed below.

\section{Decomposition}

A speculative building structure of a decomposition node is appeared in Fig-3. An issue specification is received from above within the hierarchy. If the hassle can be solved by using redesign, that is done, and the consequences back upward. If now not, then an initial decomposition is made. The use of this decomposition, preliminary specs are assigned to the sub-issues created. (This venture of specifications is a key step; the sub-issue specs are, in fact design variables at this stage.), those issues are then passed to the modules under, which might be similar in structure to the only being described. The effects back from the various sub-issues are then incorporated and examined as a total framework. If the complete system result is acceptable, it's far handed upward. If not, new subtrouble specs are assigned, and the procedure repeated. If the respecifiers have to surrender, then a new decomposition can be tried. If the re-decomposer concede rout, the framework reviews failure up the line, 
and asks for some alternate within the general issue task undertaking. Engineering products are often highly complex, involving thousands of parts and in the design of such products the interactions between the design activity and other activities such as, manufacturing are also very complex. A way which is adapted for managing the complexity in many approaches is to apply 'divide and conquer' method in which the problem is divided into smaller, more soluble, sub problems. Much research into this area has also taken place by studying how designs and design knowledge and the design process, may be subdivided, which is called as decomposition of the problem into smaller elements. An assembly may be subdivided into the subassemblies. Decomposition may be achieved in various ways, for example by dividing the problem according to the nature of the solution technique adopted, or dividing the design itself into a series of elements as shown in Fig-4. An assembly might be divided into subassemblies, and these in turn into individual components. If the design process progresses from the upper levels to the lower ones this is known as a topdown approach to design as illustrated in Table-1. Conversely, if the detailed component parameters are established first, and then the results assembled at a higher level, then this is known as bottom-up design.

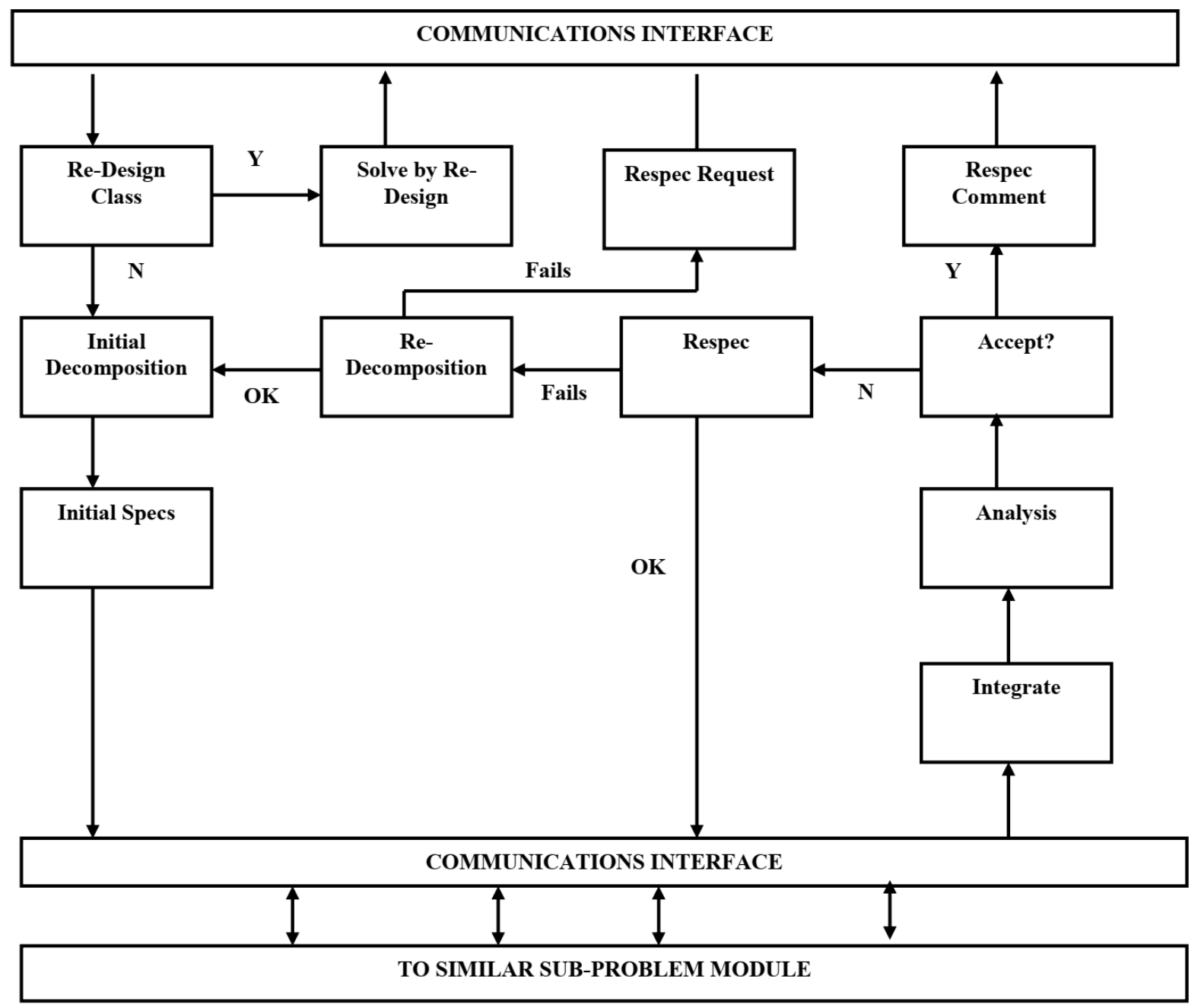

Fig-3: Speculative building structure resembling decomposition module nodes 


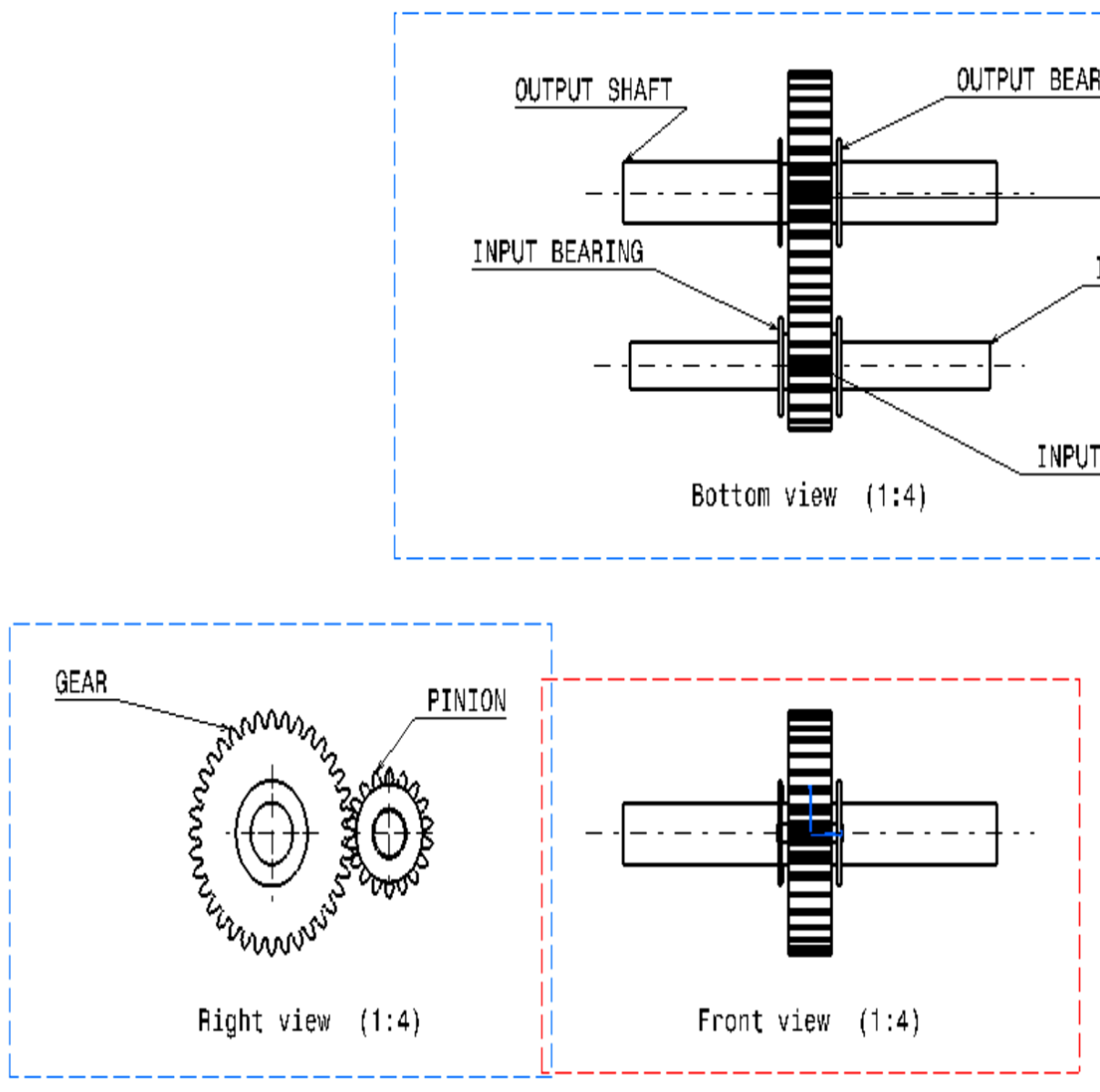

Fig-4: Components of the gearbox

Table-1: Assembly Constraints used for the gearbox

\begin{tabular}{|l|l|l|l|l|}
\hline $\begin{array}{l}\text { S. } \\
\text { No }\end{array}$ & Name of the Component & $\begin{array}{l}\text { Constrained with } \\
\text { respect to another } \\
\text { component }\end{array}$ & Type of Constraint & $\begin{array}{l}\text { Type of Constraint } \\
\text { with respect to another } \\
\text { component }\end{array}$ \\
\hline 1. & $\begin{array}{l}\text { Principal casing } \\
\text { Cover }\end{array}$ & - & Fix & - \\
\hline 2. & Output shaft & $\begin{array}{l}\text { Principal casing } \\
\text { Cover }\end{array}$ & Coincidence & Line + Plane \\
\hline 3. & $\begin{array}{l}\text { Output ball bearing } \\
2.2\end{array}$ & Output shaft & Coincidence & Line + Plane \\
\hline 4. & Output Shaft Key & Output shaft & Coincidence & Line + Plane \\
\hline 5. & Gear & Output shaft & Coincidence & Line + Plane \\
\hline 6. & $\begin{array}{l}\text { Output ball bearing } \\
2.1\end{array}$ & Output shaft & Coincidence & Line + Plane \\
\hline 7. & $\begin{array}{l}\text { Input shaft } \\
8 .\end{array}$ & $\begin{array}{l}\text { Principal casing } \\
\text { Cover }\end{array}$ & Coincidence + Angle & Line + Plane \\
\hline 9. & Pinion & Input shaft & Coincidence & Line + Plane \\
\hline 10. & $\begin{array}{l}\text { Input ball bearing } \\
1.2\end{array}$ & Input shaft & Coincidence & Line + Plane \\
\hline 11. & $\begin{array}{l}\text { Secondary casing } \\
\text { cover }\end{array}$ & $\begin{array}{l}\text { Principal casing } \\
\text { cover }\end{array}$ & Coincidence & Line + Plane \\
\hline
\end{tabular}

\section{Plan Selection and Refinement}

In many design problems the design approach can at least in part be reduced to that of identifying a generic design type and then filling in details of dimensions, materials and component arrangement. In
AI this approach is called as Plan refinement, and is a technique that originates from research into medical expert systems. There it is used to select a general treatment approach, and then to refine this to identify drug combinations and amounts appropriate to a 
particular patient. In our case, the process of selecting a type of bearing to be used, and then instantiating the values of the attributes in a frame describing that bearing, can be regarded as a simple example of plan refinement.

\section{Constraint-Based Reasoning}

The particular materials, dimensions and condition selected for a given design will be chosen to ensure that the design is fit for purpose, and that it can be made. If a dimension is such that the design breaks under load, or cannot be made, then the design conflicts with constraints imposed by the strength of its materials or manufacturing process respectively. The more general concept is that a particular design is at a point in a multi-dimensional design space, and that bounds on that space that define feasible designs are imposed by constraints as shown in figure below.

\section{NUMEROUS APPLICATIONS OF ARTIFICIAL INTELLIGENCE IN MECHANICAL SYSTEMS Artificial Neural Network (ANN) Based Mechanical Defect/Imperfection Analysis \\ Smart intuitive based issue recognizable proof} begins with the obtaining and accumulation of data which are identified with the mistakes. For separating the component, the spectra acquired from its recurrence must be acquired. These mistake highlight extraction strategies can be characterized in to two kinds to be specific factual just as model based [7, 8]. It incorporates different calculations which can process a wide range of sign that are acquired from these machines. The general procedure is appeared in Table-2 as different NN's, which includes BPNN, Radial basis feature Neural Networks (RBFNN), (SOM) and principal component analysis (PCA) are utilized.

Usually, the procedure of savvy flaw recognizable proof is done when the data sources are given towards the neuron which produces the yields dependent on the sign and issues present in the machines. By utilizing these NN's, the client who is preparing and testing the procedure need not used to ponder the total NN. The fault identifies in Mechanical building based innovation depends on the increase in the general working of the device or system dependent on the data of relative steady condition, the assessment of the consistent sign and afterward blending it with the articles identification condition, to quantify the mechanical innovation of genuine world Mechanical based machines, and to recognize the extraordinary destruction and furthermore to estimate the forthcoming position of the technology [9]. Its primary arrangement is to utilize the most recent adjustment of all the innovation which are available in prior looks into are identified with the mechanical building for staying away from blunders. Recognizable proof of mistakes in the mechanical based machines which can be connected in businesses can be effectively distinguished by the nearness of some blunder, and fix investigation strategy. Recognizable proof of mistakes or blames in Mechanical building based innovation is the result of the development of present day innovation and it depends on the innovation the executives system.

Issue recognizable proof is the key job to comprehend the fundamental indication of the mistake as flaw. The conventional of finding the mistakes is thinking based emblematic master framework. Yet, this framework discovers different blames, for example, to discover the framework which can't arrive at the fundamental stage, the capacity of an ANN is selflearning, the capacity of framework towards non-direct based mapping, capacity of figuring parallelly and resilience of mistake in structure a progressed mistake recognizable proof framework. An ANN based blunder distinguishing proof framework utilizes a contribution to discover the status of shortcoming based on its indications by doing the numerical based calculations. When all is said in done, it incorporates the interface between human furthermore, the machine-based modules, analysis and thinking of learning base, data recovery module and at long last the learning module for the framework. A portion of the NN's which are utilized for the recognizable proof of mistakes in the rotary machines, are appeared in Table- 2 .

Table-2: Several Neural Network which are utilized for the recognizable proof of mistakes in the perfunctory mechanical machineries

\begin{tabular}{|l|l|l|l|l|}
\hline Neural Networks (NN) & $\begin{array}{l}\text { Power } \\
\text { transmitting, Gears }\end{array}$ & $\begin{array}{l}\text { Rotating machine } \\
\text { element, Shafts }\end{array}$ & $\begin{array}{l}\text { Electric } \\
\text { Motors }\end{array}$ & Bearings \\
\hline Back Propagation Neural Network (BPNN) & 20 & 2 & & 21 \\
\hline Hopfield Neural Network (HNN) & & 1 & 1 & \\
\hline Self-Organizing Map (SOM) Network & & & 9 & \\
\hline Radial Basis Function Neural Networks (RBFNN) & & 21 & & 21 \\
\hline Principal Component Analysis (PCA) & 6 & & & \\
\hline
\end{tabular}

Artificial Neural Network (ANN) Based Smart Canny Indicative Framework for Rotary Equipment In the situation of issue recognizable proof in device based on mechanical building during the previous years, the usual technique or approach of deficiency recognizable proof of rotating equipment has improved. The accomplishment achieved an extraordinary monetary peak in the realistic functional usage. The proposed approach is a widespread based neural network recognizable proof framework in use of 
shortcoming distinguishing proof in pivoting equipment in fan. The distinguishing proof has two noteworthy parts. Initial one is the fan and the second one is engine. The fundamental unit of this framework can be additionally isolated into five sub parts, for like vibration-based primarily parameter, temperatureprimarily based parameter, clamor and oil based parameter.

\section{Artificial Neural Network (ANN) based totally Intelligent Analysis Device for Reciprocating Machinery \\ One of the principal factor of the movement} first-rate reciprocating machinery is it has a hard and fast of very excessive in velocity of reciprocating. Its dynamics-based totally morphology is more complicated when in comparison to the rotating machinery. Because of this nature, the identity of fault is extra difficult in nature. The previous mechanisms for failure and together with its methods carried to date for prognosis is not sufficient. Diesel engine is a reciprocal based totally device which responds to an analysis system primarily based on an included neural network. This machine is an everyday $\mathrm{NN}$ primarily based incorporated figuring out device that is constant in the errors or fault identification system of a diesel engine and its packages. Various styles of failures in the diesel engine may be labelled into performance-based totally failure and mechanical-based totally failure. The overall performance of mistake's identity on this NN based machines may be obtained more effectively the usage of an additional NN. The performance parameters of this $\mathrm{NN}$ is an input which consists of electricity primarily based, velocity based totally, stress of the cylinder, temperature of the water and so on. The various faults in the mechanical based engine is diagnosed by additional $\mathrm{NN}$ based totally systems and the incorporated NN based totally identity mechanism. The complete mechanism is formed through the combination of vibro based acoustic (VA) sign and the oil analysis system.

\section{Artificial neural network (ANN) based fault diagnosis to warm film forging press}

In the technique of production of warm forging presses, various errors may be passed off inclusive of the preventing of slider out of doors the place, stuffy automobile, the current of motor is greater, failure in lubrication and many others. These mistakes may be brought about by diverse reasons [10]. The fault prognosis of the manufacturing system of the new forging press is primarily based on the guideline reasoning and the case reasoning. The system tactics the mistakes based totally on the library after which it information the error number in the library. The algorithm that is used to analyze the similarity of case matching is as follows:

$\operatorname{res}(\mathrm{Y}, \mathrm{B})=\frac{\sum_{\mathrm{j}=1}^{\mathrm{m}} \mathrm{X}_{\mathrm{j}} \operatorname{res}_{\mathrm{j}}\left(\mathrm{f}_{\mathrm{j}}^{\mathrm{y}} \mathrm{f}_{\mathrm{j}}^{\mathrm{z}}\right)}{\sum_{\mathrm{j}=1}^{\mathrm{m}} \mathrm{X}_{\mathrm{j}}} \ldots \ldots \ldots \ldots \ldots$ Equation (1)
Where, $X_{j}$ is the load of the $j^{\text {th }}$ credit, $\mathrm{f}_{\mathrm{j}}^{\mathrm{y}}$ delineates the estimation of the $\mathrm{j}^{\text {th }}$ credit for the shortcoming $Y, f_{j}^{z}$ speaks to the estimation of $f_{j}^{z}$ of the condition $B, \operatorname{res}_{j}\left(f_{j}^{y} f_{j}^{z}\right)$ is the similarity of the mistake $\mathrm{X}$ and the recovery condition is $\sum_{\mathrm{j}=1}^{\mathrm{m}} \mathrm{X}_{\mathrm{j}}=1$.

Because the credit values are distinctive, the computation is not similar.

$$
X_{j}=f_{j} \log \left(\frac{M}{M_{j}+2}\right) \ldots \ldots \ldots \ldots \ldots . . . \text { Equation (2) }
$$

This above mentioned equation is also used to compute the similarity of the angle of loads.

\section{Artificial neural network (ANN) primarily based mechanical shape arrangement evaluation and geometric modelling}

Shape evaluation in mechanical engineering can be used to recognize the layout parameters which may be used to modal the mapping parameter [11]. Generally, the method that is used is the finite element evaluation is now changed by ANN based totally methods which will perceive in addition to for the technique of mapping. In various structure of the records which were obtained with the aid of the finite element evaluation, it's far further used for education the BPNN, the common or basic fee of the training parameter is further used by the structure analysis parameter of NN. The procedure of shape analysis and the dynamic layout is used to apprehend the parameters of modal with the system of relationship mapping. That is the overall technique of shape analysis in mechanical engineering. But the answer is too hard to examine the general mechanism. A mechanism that's used in the finite element-primarily based process referred to as the structure analysis of the records or the training of BPNN. This mechanism uses the effort of synthetic neural network as modal parameters and the output as design parameters to pick out and analyze the relationship of mapping among each of them. It can additionally be used for the modification of the general structural dynamic layout. The complex floor modelling, one of the categories of geometric modeling especially makes use of the spline feature fitting mechanism. This mechanism is extra complicated with diverse boundary situations. Changing its risks is more difficult. It wishes massive calculations and steps. The nonlinear mapping technique of ANN utilized in geometric modeling is a complicated step inside the mechanical engineering. The calculation is with the particle surface of coordinates as $\mathrm{X}, \mathrm{Y}$ that's given as enter and the coordinate $\mathrm{Z}$ is given as the output. These coordinates are chosen for schooling the sample set of ANN. This can be recognized by means of the curved formed floor of modeling. 
Artificial Neural Network (ANN) primarily based Mechanical Layout and Optimization

Shape of the mechanical engineering-based totally systems and machines are complicated these days. The complexity arises in those mechanical engineering-based totally structures due to its static homes consisting of the stiffness, electricity, pressure, and so forth. And the dynamic response homes which include the pressure, displacement, pace, acceleration, frequency and vibration are considered as the optimization problem [12] which is included in nature. This included hassle is primarily based on mathematical calculation. The optimization troubles are categorized primarily based on size, topology and overall performance. Various optimization methods based totally on mathematical based totally programming is inadequate to make a distinction in these forms of optimization problems. The Hopfield $\mathrm{NN}$ has belongings of maximum energy tending closer to a strong kingdom. Due to these assets, the above-noted sorts of optimization mistakes can be changed closer to a power feature answer of ANN. The dynamic machine of ANN is one of the property of the objective characteristic is the point of minimal, from the point of initial kingdom. The ANN can also be used in the minimal point so as to complete the calculation of optimization. The utility of AI in fixing the optimization troubles is depicted in [13]. In their paper, the authors explained the utility of AI based strategies in solving numerous optimizations of numerous problems [14]. This system is used for optimizing diverse problems together with second structures and the 3D structures, composites structures, vibrating systems; it can be extensively utilized to pick out the acoustics problem. The optimization of thermoelectricity based trouble based totally on coupled area is performed in [15]. Coupled area is described because the attentions of our bodies which have been subjected to concurrent knock of thermal and mechanical fields. Another, software of the AI primarily based systems is the optimization and identity of certain numerical values which fits for the composite systems, that's having a percentage of excessive electricity-to-weight while in comparison with frequently used materials.

\section{CONCLUSION}

Artificial Intelligence can be used very effectively and efficiently for the design of the mechanical system. It is successfully applied for the design of gearbox, which reduces design time and cost to a very large extent. Hence, Artificial Intelligence will outcome in transfiguring and reforming industrialized surroundings at the traces of enterprise 4.0 or Internet of Things. Artificial Intelligence in production prompts in the Just-in-Time Manufacturing. In this paper, a broad audit with respect to the uses of the Artificial Intelligence, in conjunction with its connection between the mechanical building for the method of mechanical imperfections identification and design layout configuration is proposed. This paper accommodates the précis or synopsis related to the precise utilization's of Artificial Intelligence in the field of mechanical engineering. Several applications, like errors identification, Analytic indicative Framework machine, mechanical shape and structure investigation, and mechanical layout plan are notably inspected. This study uncovers that the Artificial Intelligence based smart system is broadly utilized generally in the total mechanical engineering designing area. This paper likewise presumes that the Mechanical Engineering and designing field can be effectively combined with different other Artificial Intelligence based innovation era to make it progressively successful to improve in the mechanical framework. Future outlook is to actualize the Artificial Intelligence based frameworks for featuring hybrid primarily smart design plan layout of mechanical frameworks for the reason of watching, controlling, the errors diagnosing framework dependent on Artificial Intelligence, like the Fuzzy Logic \& Neural grid Systems for enhancing the prevailing situation with mechanical engineering and design.

\section{DECLARATION OF CONFLICT OF INTEREST}

The authors declare that they have no conflict of interest with respect to the research, authorship, and/or publication of this article.

\section{FUNDING}

The author's doesn't receive any research fund or grant from any organization.

\section{ETHICAL APPROVAL}

This article does not contain any studies with human participants or animals performed by the author.

\section{ACKNOWLEDGEMENTS}

The authors wish to acknowledge the Department of RIC, IK Gujral Punjab Technical University, Kapurthala, Punjab, India. This work was completed in part with resources provided by CSIRCentral Leather Research Institute, RCED, laboratory. The authors appreciatively acknowledge the support of CSIR-Central Leather Research Institute, RCED, laboratory for providing opportunity to conduct this research task.

\section{REFERENCES}

1. Theng, C. D., Ismail, N., Voon, W. S., \& Rahman, W. A. (2007). Knowledge based system for mechanical CAD design, The 2nd National 'Intelligent Systems and Information Technology' Symposium (ISITS'07), Oct 30-31, 2007, ITMA UPM, Malaysia, 218-224.

2. Xie, P., Kang, Y., \& Zhang, Q. (2005). Research on Application of Development Method of Knowledge Base in the Integrated System for ICAD, Sixth International Conference on 'Parallel and Distributed Computing', Applications and 


\section{Technologies (PDCAT'05) 0-7695-2405-2/05, 2005.}

3. Mogan, G., \& Butila, E. (2006). Production Engineering Book Chapter, Gheorghe Mogan, Eugen Butila, Expert system to design mechanical systems with gears, 143-162.

4. Cecil, J. (2001). Computer-Aided Fixture DesignA Review and Future Trends. International Journal of Advanced Manufacturing Technology 18: 790793.

5. Zhongtu, L., Qifu, W., \& Liping, C. (2006). A knowledge-based approach for the task implementation in mechanical product design. International Journal of Advanced Manufacturing Technology, 29, 837-845.

6. Basak, H., \& Gulesin, M. (2004). A Feature based parametric design program and Expert system for design. Mathematical and Computational Applications, 9(3), 359-370.

7. Szczepanik, M., \& Burczynski, T. 2012. Swarm optimization of stiffeners locations in 2-D structures. Bulletin of the Polish Academy of Sciences Technical Sciences, 60(2), 241-6.

8. Landay, J. A., \& Myers, B. A. (2001). Sketching interfaces: Toward more human interface design. IEEE Journal of Computers, 34(3), 56-64.

9. Meesad, P., \& Yen, G. G. (2000). Pattern classification by a neuro fuzzy network: application to vibration monitoring. ISA Transactions, 39(3), 293-308.

10. Mishra, L., \& Saraswat, U. (2017). Impact of Artificial Intelligence in the Mechanical Engineering. International Journal of Mechanical and Production Engineering, 5(7), 9-11.

11. Honey. (2016). Role of Artificial Intelligence in Mechanical Engineering. International Journal of Technology \& Engineering, 1(1), 1-6.

12. Zhao, L., \& Sheng, Z. (1996). Combination of discrete cosine transform with neural network in fault diagnosis for rotating machinery. Proceedings of the IEEE International Conference on Industrial Technology (ICIT'96), 450-4.

13. Quintana, G., Garcia-Romeu, M. L., \& Ciurana, J. (2011). Surface roughness monitoring application based on artificial neural networks for ball-end milling operations. Journal of Intelligent Manufacturing, 22(4), 607-617.

14. Engin, S. N., \& Gulez, K. (1999). A wavelet transform-artificial neural network (WT-ANN) based rotating machinery fault diagnostics methodology. Proceedings of the IEEE-EURASIP Workshop on Nonlinear Signal and Image Processing 2, 714-720.

15. Baillie, D., \& Mathew, J. (1994). Diagnosing Rolling Element Bearing Faults with Artificial Neural Networks. Acoustics Australia, 22(3), 7984. 